\title{
Professores, violência e convivência social: por uma cultura da paz
}

\author{
Teachers, violence, and social coexistence: \\ for a culture of peace
}

\author{
Kátia Silva Cunha ${ }^{[a]}$, Matheus Silva Cunha ${ }^{[b]^{*}}$ \\ [a] Universidade Federal de Pernambuco (UFPE/PE), Caruaru, PE, Brasil \\ ${ }^{[b]}$ Universidade Federal de Pernambuco (UFPE/PE), Recife, PE, Brasil
}

\section{Resumo}

Este trabalho discute o fenômeno da violência, principalmente quando esta ocorre no contexto da escola. Para fomentar este estudo, foi realizada uma revisão narrativa da literatura e para tal, priorizamos artigos sobre a temática, além de informações trazidas por reportagens, acessadas diretamente nos sites. Para a busca dos artigos, foram utilizadas as seguintes palavras-chave: violência e convivência na escola, violência, professores e cultura da paz. A proposta é tentar buscar responder como a cultura da paz pode amenizar o fenômeno da violência na escola? Para tal, focaremos em duas perguntas:

KSC: Doutorado em Educação, e-mail: kscunha@gmail.com MSC: Mestrando em Ciência Política, e-mail: mscunha@gmail.com 
Quais as raízes da violência? Como professores podem lidar com o fenômeno da violência no ato de desenvolver uma prática pedagógica firmada na cultura da paz? Afirmamos que a violência está associada a diferentes causas e que já existem iniciativas que apontam para uma solução, entretanto afirmamos, que o tema da violência no meio escolar não pode mais passar despercebido pelos formuladores das políticas, nem por aqueles que estudam este fenômeno a partir de uma perspectiva mais prática, como ocorre no campo da Teologia. Assim, espera-se contribuir com o estudo da violência, ancorando-a também no viés da espiritualidade, no sentido de recuperação e comprometimento com a alteridade, cuja finalidade é a promoção de uma cultura da paz.

Palavras-chave: Violência. Violência na Escola. Cultura da Paz. Espiritualidade.

\section{Abstract}

This paper discusses the phenomenon of violence, mainly when it occurs in the school. To fuel this study, we made a literature review, prioritizing papers about the theme, alongside information brought by news articles, accessed directly from the websites. To search the papers, we used the following keywords: violence and school coexistence, violence, teachers and peace culture. The proposition is to answer: how a culture of peace can mitigate the phenomenon of violence in the schools? To such ends, we will focus on two questions: what are the roots of violence? How can teachers deal with violence in the act of developing a pedagogical practice based on the culture of peace? We affirm that violence is associated with different causes and that there are initiatives that point towards a solution, however we claim that the theme of violence in the school environment can no longer go unnoticed by policymakers, nor by those who study this phenomenon from a more practical perspective, as occurs in the field of Theology. Therefore, we expect to contribute with the study of violence, anchoring ourselves in the way of spirituality, in the sense of recovery and commitment to the other ones, whose finality is the promotion of a culture of peace.

Keywords: Violence. Violence in school. Culture of Peace. Spirituality. 


\section{Introdução}

Uma frase célebre muito utilizada sobre a prática da violência, advém de Thomas Hobbes (1588-1679), a qual afirma ser o homem o lobo do próprio homem (HOBBES, 1974). Essa máxima evidencia o grau de violência e de comprometimento das relações humanas, a partir de atos de injustiça, competitividade, egoísmo, inveja, ou seja, expressões da maldade instalada.

Atos de violência nos assustam, apavoram e fazem-nos questionar a humanidade. Enquanto herdeiros da tradição iluminista, crescemos convictos que a barbárie foi abandonada nas "Trevas do antigo e medieval", e que o projeto de civilização ancorado na racionalidade e na busca do conhecimento, nos conduziria às luzes de um desenvolvimento social e cultural, emancipação e distanciamento das superstições, crenças e divindades que controlam os desejos e ações dos homens.

Dessa forma, atos de violência nos confrontam com o fracasso do projeto iluminista de humanidade, fazendo-nos crer que a barbárie é constituinte do humano e sempre esteve presente no berço da civilização moderna, a Europa (DURAS, 1986). Isso nos constrange de uma forma mais acentuada, quando os atos de violência são exercidos no espaço da escola, principalmente quando se pensa sobre a crise gerada no âmbito da eficácia socializadora que deveria ser desenvolvida na escola. Atos de violência distanciam-se, ainda, do sentido de alteridade manifesta no fenômeno da espiritualidade, a partir da máxima cristã, amar ao próximo como a si mesmo, expressa no Evangelho de Marcos 12,31. Sendo que não "há outro mandamento maior do que este". De fato, essa máxima revela o sentido da vida relacional a ser mantida em processos de convivência entre indivíduos.

Diante dessa questão posta, este artigo pretende refletir de forma interdisciplinar sobre o tema da violência, relacionando-o a sala de aula, especificamente ao trabalho de mediação de professores, a fim de não apenas problematizar esse espaço, chamado escola, mas de percebê-lo como lócus possível de construção da cultura da paz, de comprometimento de promover e vivenciar o respeito a vida e dignidade de cada pessoa sem discriminação ou preconceito. Não pretendemos fechar aqui a polêmica sobre o tema, nem buscar uma generalização em relação a todas as escolas e professores, como se todas as escolas e professores fossem da mesma 
forma. Compreendemos como Ball (2016, p. 18), “que as escolas são constituídas de diferentes tipos, de diferentes gerações, de professores com diferentes disposições em relação ao ensino e à aprendizagem", o que torna este espaço diverso, multifacetado e plural.

Trata-se de uma reflexão sobre o fenômeno da violência, principalmente quando esta é direcionada no contexto da escola, atingindo, ainda, os docentes de uma forma mais direta. Para fomentar este estudo, foi realizada uma revisão narrativa da literatura sobre o tema. Este tipo de metodologia tem o objetivo de sintetizar ideias sobre determinado tema, não fazendo restrição para a busca dos trabalhos selecionados, podendo ser: artigos, dissertações, teses, livros, revistas, entre outros (HOLANDA, 2013).

Neste artigo foram priorizados artigos, informações trazidas por reportagens e sites. Para a busca foram utilizadas as seguintes palavras-chave: violência e convivência na escola, violência, professores e cultura da paz.

Dessa forma, buscaremos elucidar o motivo pelo qual a violência pode ser tratada no espaço da convivência escolar. Para tal, focaremos em algumas perguntas: Quais as raízes da violência? Como os professores podem lidar com o fenômeno da violência no ato de desenvolver uma prática pedagógica firmada na cultura da paz? E ainda, seria possível olhar para esta realidade com esperança? Seria possível contar com outra alternativa para a violência? E por fim, por que a espiritualidade não é considerada na esfera dos relacionamentos, sendo ela um caminho de materialização de uma cultura da paz?

São muitas as questões levantadas e de fato não sabemos ao certo se as mesmas serão respondidas. O certo é que elas nos levam a refletir sobre este fenômeno e como isso pode embaraçar não só a convivência escolar, mas a convivência humana.

\section{Raízes da violência}

Pensar nas raízes da violência é tentar compreender seus fundamentos, ou seja, a forma que se origina na realidade social, ou seu 
ponto de partida. Tanto é assim, que este fenômeno é considerado em diferentes perspectivas e, uma delas, é a religiosa ${ }^{1}$.

De acordo com Odalia (2004, p. 13), "o viver em sociedade foi sempre um viver violento". Mas, segundo Butler (2015, p. 239), “esse tipo de afirmação funciona como um argumento transcendental [...]. O termo "violência não descreve exatamente o poder ou a força mediante os quais operam". Ainda, para Laclau e Mouffe (2015, p. 58): "Evitemos qualquer tentação de volta às "origens", mas partimos de algum lugar". Assim, nesse artigo partiremos dessa recorrente afirmação, pois tem sido muito utilizada para explicar o comportamento humano diante de ações e palavras que ferem e matam. Nesse sentido, a violência seria uma característica humana, ou inerente ao humano. Mas esta não é a única explicação.

Outra definição a ser considerada é que o fenômeno da violência se apresenta como algo necessário e bom, resultado do esforço humano para sobreviver na natureza, sendo assim uma agressividade instintiva que permite permanecer vivo. Para outros ainda, a violência é resultado de uma "sociedade polarizada, que torna visível de maneira sem precedentes o hiato entre ricos e pobres, indígenas e não-indígenas, afrodescendentes e brancos" (BLANCO, 2008, p. 24). Tais afirmações nos colocam de mãos atadas, principalmente no que diz respeito às relações escolares, visto que essas implicariam em um espelhamento imediato das relações extraescolares, e a solução estaria na impossibilidade de uma sociedade sem conflitos. Deste modo, como afirma Guimarães (1996) precisamos pensar esse espaço de convivência social, chamado escola. Afinal,

A instituição escolar não pode ser vista apenas como reprodutora das experiências de opressão, de violência, de conflitos, advindas do plano macroestrutural. É importante argumentar que, apesar dos mecanismos de reprodução social e cultural, as escolas também produzem sua própria violência e sua própria indisciplina (GUIMARÃES, 1996, p. 77).

1 Entre as possibilidades de referência, encontramos na Bíblia Sagrada dos cristãos que: "Não há nenhum justo, nem ao menos um” (Rm 3,10), "Porque do coração procedem os maus intentos, homicídios, adultérios, imoralidades, roubos, falsos testemunhos, calúnias, blasfêmias” (Mt 15,19).

Rev. Pistis Prax., Teol. Pastor., Curitiba, v. 10, n. 1, 36-58, jan./abr. 2018 
Para cada uma dessas explicações, uma solução seria legitimar um espaço de controle da violência, seja com a criação de uma instituição que estabeleça regras e normas de convivência, como indicado por Hobbes (1974), em sua obra magistral o Leviatã, ou a criação de políticas que promovam o bem-estar social, a distribuição das riquezas e a equidade. Nesse sentido, há a necessidade do investimento em políticas educativas, com um enfoque da educação como direito humano, que possibilite o exercício dos demais direitos humanos (ONU, 1948).

A solução apontada para o controle da violência, ainda, permite que se "amplie as capacidades das pessoas para o exercício de sua liberdade e consolide comunidades pluralistas baseadas na justiça" (BLANCO, 2008, p. 28), direcionando dessa forma para a possibilidade de construção de uma sociedade sem conflitos e divisões, ancorada no consenso racional. Entretanto, defendemos que essa utopia, é impossível, pois "conflito e divisão [...] não são nem distúrbios que infelizmente não podem ser eliminados, nem impedimentos empíricos que impossibilitam a plena realização de uma harmonia inatingível [a qual] não obstante deve constituir o ideal rumo ao qual lutamos" (LACLAU e MOUFFE, 2015, p. 46).

Blanco e outros autores (2008, p. 25) afirmam, ainda que a polarização da sociedade não deve ser considerada a única causa, visto que a violência está associada a diferentes causas, "[...] como resultado das diferenças entre o consumo simbólico e o consumo material, entre nível educacional e acesso a empregos produtivos, entre o desejo de autonomia e a impossibilidade de materializá-la".

Nas afirmações acima, mesmo na consideração de que não existe uma causa única, as políticas educativas deveriam ser "implantadas", como se uma boa política pudesse garantir a formação humana desejada, firmada nos pilares da justiça, equidade, liberdade. Entretanto, como afirma Butler (2015, p. 250): "reconhecer a violência não garante, de modo algum, uma política de não violência".

Nesse sentido nos perguntamos: Seria possível a construção de uma política educativa que garantisse um projeto de formação que possibilitasse a justiça social, o exercício dos direitos humanos, que capacitasse as pessoas para liberdade e para a construção de uma cultura 
da paz? Buscaremos responder à essa inquietação, mas não antes de apresentar o que alguns estudos apontam sobre a violência.

\section{Violência: ponto inicial de referência}

Cerqueira e Lobão (2004) enfatizam que os estudos teóricos sobre a violência caminham em duas direções, o primeiro focado nas motivações individuais e nos processos que levariam as pessoas a se tornarem criminosas e, o segundo, nas tentativas de se compreender as relações entre as taxas de criminalidade e suas variações entre diferentes culturas e organizações sociais.

Outros estudos também apontam como causa da violência a impunidade que desencadeia a desconfiança sobre a justiça e a busca desta por meios não legais (ADORNO, 2002); ainda há os que indicam os traços biológicos dos indivíduos, a ingestão de álcool ou drogas mais potentes; as questões ambientais e geográficas - escola perto de áreas de conflito como favelas, por exemplo — , e a infraestrutura (RAINE, 2015). Fatores que ocasionam tipos de exclusão territorial. "A exclusão territorial faz indivíduos, famílias e comunidades particularmente vulneráveis, abrindo espaço para a violência e o conflito" (ROLNIK, 1999, p. 100). Ainda autores como Briceño-León (1999) e Zaluar et al. (2001) consideram a violência um fenômeno multideterminado, pois muitos são os fatores que a afetam.

Diante de tantas (im)possibilidades de identificação dos condicionantes, podemos inferir que não há uma raiz isolada. Todas as supostas causas da violência são causas umas das outras, também. Por exemplo, desigualdade de renda está associada à baixa escolaridade, que por sua vez está associada a altas taxas de criminalidade. O que ocorreu primeiro: a desigualdade, ou a deficiência educacional, ou a criminalidade causa ambas? Isolar esses efeitos é uma tarefa difícil. De toda forma, nos perguntamos se existe uma relação entre violência e nível educacional.

Pesquisas apontam para uma correlação possível entre educação, violência/criminalidade. Batella e Diniz (2010, p. 154) afirmam: 
A relação entre educação e criminalidade pode ocorrer de forma direta ou indireta. De forma direta, por exemplo, através de uma maior propensão que grupos de indivíduos detentores de baixos níveis educacionais apresentam em recorrer à violência física para mediar conflitos e desavenças pessoais [...]. De forma indireta, a educação passa a ser uma pré-condição ao acesso das pessoas a uma melhor qualificação profissional e, consequentemente, a uma renda melhor. Baixo nível educacional, portanto, significa dificuldade de acesso à renda, ocasionada por um mercado de trabalho que exige qualificação.

A Agência de Justiça Juvenil e Prevenção da Delinquência, com sua sede nos Estado Unidos, desenvolveu um mapeamento extensivo dos caminhos pelos quais uma criança torna-se um infrator, adquirindo comportamentos violentos e mantendo-os durante a fase adulta. Segundo os autores do estudo ${ }^{2}$, os três possíveis caminhos são: (1) o caminho do conflito de autoridade, (2) o caminho da dissimulação, que envolve a prática de pequenos furtos, e (3) o caminho evidente, mais facilmente perceptível, em que a criança pratica agressão física e bullying.

O interessante desse estudo é que os "caminhos" da delinquência entre crianças e adolescentes possuem raízes nos lares, e não necessariamente nas escolas. Isso sugere que maus tratos dos pais, relação tumultuosa com eles (especialmente com a mãe), exposição à linguagem imprópria e a fatores de risco (consumo de drogas, espancamentos, bebida alcoólica etc.) são as causas mais prováveis de comportamento delinquente persistente. Mobilizando dados dos EUA, os autores concluem que os pais frequentemente não procuram ajuda nas escolas, nem de outros profissionais.

Concluímos que a escola possui um papel de interrupção de um ciclo do qual a criança, uma vez inserida, dificilmente escapa. Para tal, é necessário que conte com capital humano especializado e, mais importantemente, dedicado a esta tarefa. Se os professores - os agentes da escola com maior contato com os alunos - não se interessam pelo

2 ThORnBerRY, T.; HUIZINGA, D. e LOEBER, R. The Causes and Correlates Studies: Findings and Policy Implications. Office of Juvenile Justice and Delinquency Prevention, 2004. 
ambiente em que agem, parte importante do papel da escola em romper ciclos viciosos de delinquência é perdido ${ }^{3}$.

A pouca empatia dos professores pode estar vinculada a pouca valorização profissional ${ }^{4}$, às precárias condições de funcionamento da escola, aos baixos resultados dos alunos, ao excesso de cobrança e pouco retorno financeiro do serviço, ocasionando uma não identificação com alunos e alunas, e um não pertencimento ao espaço escolar. Esse distanciamento os tornaria alvos de violências. Nesse sentido, Carvalho Neto (2010), afirma que o professor deve buscar uma relação de empática, baseada na afetividade, no respeito e na atenção individualizada. Entretanto nos assevera Freire (1985, p. 161): "reinsistir em que não se pense que a prática educativa vivida com afetividade e alegria, prescinda da formação científica séria e da clareza política dos educadores ou educadoras".

Uma questão é entender porque alunos se voltam contra professores; outra é explicar como isso ocorre. De acordo com Collins (2009), seres humanos são particularmente ineptos e incompetentes em praticar violência física, dado que a violência potencial é abortada por uma barreira de tensão e de confronto. Isso faz com que a violência costume não passar de ameaças, incluindo insultos e gestos obscenos. Contudo, existem formas pelas quais a barreira de tensão e medo pode ser superada, gerando violência de fato. A mais comum delas é o ataque ao mais fraco.

A violência de muitos contra um é muito mais fácil, dado que o inimigo estaria indefeso, incapaz de reagir, suspendendo o medo potencial do agressor em ser ferido. Isso pode explicar como alunos se voltam contra professores em sala de aula: só há um professor, e vários alunos. A questão principal a se saber não é porque existe violência escolar, e sim porque não existe mais do que já se vê. Ou seja, existem fatores exógenos que controlam ou impedem a violência escolar? A conclusão preliminar a que chegamos é que esses mecanismos transformam o professor em fonte de autoridade, ou geram empatia entre professor e alunos, superando o potencial para a violência.

3 É de se especular se situações em que a violência é praticada contra os próprios professores não são situações em que a escola por si só será incapaz de resolver, ou amenizar, o problema.

4 Nos questionamos se não seria este fator, também uma forma de violência contra os professores e professoras.

Rev. Pistis Prax., Teol. Pastor., Curitiba, v. 10, n. 1, 36-58, jan./abr. 2018 
A que tipo de autoridade crianças/adolescentes/jovens responderiam? Primeiramente aos pais. A falta de supervisão parental ${ }^{5}$ é um componente basilar para se compreender porque alunos se voltam à violência dentro das escolas. Ou seja, em casos de forte supervisão parental, a probabilidade de ocorrer atos violentos dentro das escolas diminui. Isso se alinha com o entendimento de que o desapego de alunos e professores em relação ao ambiente escolar motiva maior violência. Professores e alunos distantes dificilmente se preocupam com a participação dos pais no processo educativo, de modo que não há supervisão eficaz. Acrescentamos, ainda, os resultados da pesquisa desenvolvido por Laterman (2000, p. 152), onde a pesquisadora aponta que "ausência de poder (seja da sociedade em geral, dos educadores, dos pais e de valores) que a isso se oponha", facilitam o avanço da violência.

Seguindo essa linha de raciocínio, nos perguntamos adiante: quais fatores levam professores e alunos ao distanciamento emocional do ambiente escolar? E ainda, seria possível reverter isso, a partir de um projeto fundamentado na cultura da paz?

\section{Professores, violência e cultura da paz}

Poderíamos retomar esta reflexão com alguns outros questionamentos: para que serve a escola? Qual a sua função? De uma forma bem geral, podemos assim estabelecer que a escola é um espaço sistematizado de trabalho com um objeto próprio: o conhecimento na forma de saber escolar. Tal definição, mesmo muito geral, coloca-nos diante de outras perguntas: Que espaço seria adequado para o trabalho com o conhecimento? E que profissional estaria habilitado para esse trabalho sistematizado? Que conhecimento é este legitimado a ser a ser ensinado? Por quem? E para quem? Para que? Como?

Quando estabelecemos que o espaço da escola é um local específico de trabalho para um objeto próprio, afirmamos o privilégio deste espaço, o domínio de ferramentas para o seu exercício, e um profissional que o qualifica. Assim, podemos afirmar como Hernández (1998, p. 86-87), que:

5 Que seria um proxy de más relações entre pais e filhos. 
A finalidade do ensino é promover nos alunos, a compreensão dos problemas que investigam. Compreender é ser capaz de ir além da informação dada, é poder reconhecer as diferentes versões de um fato e buscar explicações além de propor hipóteses sobre as consequências dessa pluralidade de pontos de vista. Compreender é uma atividade cognoscitiva e experiencial, de tradução-relação entre um original, ou seja, uma informação, um problema, e o conhecimento pessoal e grupal que se relaciona com ela.

Para as atividades de ensino, precisamos de um profissional, pois "a tarefa de ensinar é uma tarefa profissional que, no entanto, exige amorosidade, criatividade, competência científica, mas recusa a estreiteza cientificista, que exige capacidade de brigar pela liberdade sem a qual a própria tarefa fenece" (FREIRE, 1997, p. 9). Uma tarefa profissional que exige descobrir, conhecer, experimentar, em um espaço onde se possa criar e brincar, que tem alguém que ajude a caminhar, a compreender o mundo, relacionar-se com o mundo e com os outros, resolver problemas, explicar, investigar, escolher. "O ensino [...] Não é uma simples transmissão de um saber, mas é igualmente portador de uma intenção cultural" (CHARLOT, 2005, p. 95).

Neste sentido, é possível perceber a natureza relacional que é estabelecida entre docentes e discentes. É essa natureza relacional que oportuniza a convivência entre diferentes, o respeito e a busca pelo outro. Essa busca se impõe por intermédio do sentimento de alteridade. A alteridade é o primeiro passo para a concretização de uma proposta fundamentada na cultura da paz. A tomada sobre si do destino do outro implica responsabilidade pelo outro: todos os homens são responsáveis uns pelos outros. Emerge aqui a ideia de um novo humanismo que traz no seu bojo a manifestação visível do amor pela justiça, pois a justiça tem no amor a sua fonte inexaurível: o amor deve sempre vigiar a justiça. "O humanismo é a concretização da misericórdia, da acolhida, da abertura incondicional ao outro, da responsabilidade" (MELO, 2003, p. 267).

O processo cultural em andamento, em sua constante mutabilidade, coloca em risco os processos formativos das identidades pessoais. Além disso, obriga o indivíduo a fazer escolhas numa solidão crescente, sem os suportes e as seguranças que marcam o ritmo da sua maturidade. Nesse contexto cresce a cultura da dúvida, da ansiedade, da agressividade e do conflito. Trata-se de ativar atitudes de respeito, de acolhida, ensinar que o amor é capaz de construir identidades abertas, aptas a construir uma 
cultura de paz, a aprender continuamente e, ao mesmo tempo, a sentiremse cidadãos do mundo, além do que da pátria.

A cultura da paz é uma forma de reconhecer o lugar ocupado pela dimensão da espiritualidade. A espiritualidade é a marca que tecemos sobre o espaço ocupado. É uma forma de viver a fé a partir de um impulso da graça para participar da vida divina na nossa trajetória terrestre, pois a consumação só terá lugar quando Deus será tudo em todos (1Cor 15,28). Tanto é assim que:

É no contexto das vivências originárias que nós - desde nossos ancestrais, em diferentes culturas - nos descobrimos situados na terra como o húmus fértil do chão (húmus=homo), e, ao mesmo tempo, ligados ao céu, cuja observação nos abre a novas dimensões e conexões existenciais (religado, conectado = religiosus). Assim, nossa humanidade não se define apenas pela linguagem (homo loquens), habilidade (homo faber), arte (homo aestheticus) e inteleção (homo sapiens), mas também por nossas conexões com o mistério e o transcendente manifestos no mundo (homo religiosus) (MAÇANEIRO, 2011, 9-10).

Não há, pois, como negar ou se distanciar da espiritualidade, visto aquilo que é revelado por ela. Ela imprime um modo de ver o mundo. Ela informa sobre a nossa cosmovisão. Afinal, "o religioso é o que há de mais profundo e basilar na multidimensionalidade da vida" (RUSSEL, 2007, p. 45). E se assim o é, isso requer cuidado, atenção e, sobretudo, reflexão sobre esta dimensão no contexto das relações humanas. A verdadeira vida não se descreve, experimenta-se, vive-se.

É preciso, ainda, reconhecer a escola como espaço de ambiguidade, ou seja, caracterizada por ser espaço do passado (ensino dos conhecimentos historicamente acumulados; instituição secular, e de verdade), mas ao mesmo tempo é um espaço do presente, tentando responder aos reptos da sociedade por inovação, por busca de novas relações com o mundo e com outros humanos, e um espaço de futuro, propondo uma formação para a sociedade que ainda será, que se constituirá em cada um dos alunos e alunas que pela escolarização passam. Isso coloca um desafio imenso para docência, "pois é de seu ofício servir como mediador entre o velho 
e o novo, de tal modo que sua própria profissão lhe exige um respeito extraordinário pelo passado (ARENDT, 1992, p. 243-244).

Na perspectiva aberta pela mediação, há que se pensar numa proposta que articule a presença da alteridade, o respeito à vida, a diversidade e a convivência pacífica entre os sujeitos. Essa proposta não é simples, mas pode ser uma possibilidade no enfrentamento do fenômeno da violência. Assim, cabe à escola, enquanto instituição formadora, promover também uma determinada formação, que vise a autonomia, a solidariedade, formação crítica e espiritual do ser humano. Diante disso, pode-se compreender o sentido de ser da espiritualidade, não com o propósito de efetivação proselitista ou de massificação religiosa. Sua atuação perpassa a "parte essencial da existência humana, entendida como uma maneira de experimentar o mundo, de viver, de interagir com outras pessoas e com o mundo, envolvendo um sem-número de maneiras individuais ou coletivas de pensar, olhar, falar, sentir, mover-se e agir (PORTAL, 2004, p. 71).

Há de ressaltar, porém, que tal como o ditado popular, nem tudo é um "mar de rosas", a insatisfação com a profissão tem sido a tônica e talvez esteja nesse fator uma barreira para esta vivência relacional. Afinal: "como ensinar aqueles e aquelas que não querem aprender? Por que deveriam os sujeitos se envolverem na atividade de aprender se ao final serão todos aprovados mesmo?". Ou ainda, "por que investir tanto tempo estudando para ser professor, se qualquer um pode assumir a condução da aprendizagem dos alunos, sem formação para o exercício profissional?" Agregada à insatisfação, os noticiários estão repletos das agressões sofridas pelos professores. A título de exemplo, seguem alguns casos notificados em diferentes redes nacionais:

Um professor de 59 anos foi agredido por um aluno de 16 na Escola Estadual Bento Abelaira Gomes, no Jardim Antunes, em São José do Rio Preto (SP). A agressão foi na sexta-feira (11), mas o caso foi registrado na polícia apenas nesta segunda (14). O motivo das agressões seria por causa de um celular 6 .

6 ESTUDANTE agride professor após pedido para desligar celular na aula. G1, Rio Preto e Araçatuba, março, 2016. Disponível em: <http://g1.globo.com/sao-paulo/sao-jose-do-rio-preto-aracatuba/noticia/2016/03/ estudante-agride-professor-apos-pedido-para-desligar-celular-na-aula.html>. Acesso em: 24 jun. 2017. 
Um professor de 54 anos foi agredido por um aluno em uma escola estadual no bairro São João, em Pouso Alegre (MG) na tarde desta quarta-feira (15). De acordo com o boletim de ocorrência da Polícia Militar, a agressão teria acontecido após uma discussão entre os dois. Ainda conforme o boletim, o professor contou que tinha saído da sala para atender outro estudante e quando voltou pediu para o aluno, que tem 16 anos, colocar uma bola em cima da mesa. Os dois discutiram e o menor atacou o educador com uma das mesas da sala ${ }^{7}$.

Há três anos a professora Maria Ladjane de Araújo, 53 anos, toma diariamente uma medicação para minimizar as convulsões que sofre em decorrência da violência vivida em outubro de 2010. A gestora da Escola Modelo Infantil Santa Joana, em Caruaru (PE), atravessava a rua quando um homem avançou em sua direção e The empurrou. Ela caiu de cabeça no meio-fio, sofreu traumatismo craniano e teve um edema frontal. O agressor é pai de dois alunos que estudavam na instituição. Na época, a imprensa local noticiou que o homem estaria contrariado por ter sido chamado na escola para conversar sobre o comportamento da filha.

G.A.P é professor da rede pública do interior de Minas há 19 anos e há seis está em ajustamento funcional por causa de agressões dentro das escolas. $O$ caso, que aconteceu em 2007, deixou traumas que até hoje não foram superados. $O$ educador de 45 anos, que prefere não revelar o nome, contou que em um dia de trabalho um dos alunos estava sem nota e não queria refazer a prova. Bastou para que o professor sofresse mais do que ameaças por parte do adolescente ${ }^{8}$.

Conforme relatos acima, a violência extrapola os xingamentos, chegando a agressão, sendo esta exercida por pais de alunos e alunos, por motivos pífios - desligar o celular, refazer uma prova, ser chamado à escola para conversar - , e tem atravessado a vida dos professores, que passam a sentir-se sob ameaça permanente, quer real ou imaginária. O medo do aluno. Pesquisas ainda apontam que as práticas de agressões, tanto entre os alunos como contra os professores, são mais comuns nos estabelecimentos de grande porte e nas capitais (BATISTA; EL-MOOR, 1999).

7 PROFESSOR é agredido por aluno em escola estadual em Pouso Alegre, MG. G1, Sul de Minas, Minas Gerais, junho, 2016. Disponível em: <http://g1.globo.com/mg/sul-de-minas/noticia/2016/06/professor-eagredido-por-aluno-em-escola-estadual-em-pouso-alegre-mg.html>. Acesso em: 24 jun. 2017.

8 CHAGAS, A. Violência contra professores. Quando a tarefa de ensinar vira caso de violência. Terra, 2010. Disponivel em: <http://noticias.terra.com.br/educacao/infograficos/violencia-contra-professores/>. Acesso em: 24 jun. 2017. 
O deslocamento de sentidos sobre a profissão docente, do lugar de autoridade e legitimidade para o lugar da fragilidade e desrespeito, tem desenvolvido um progressivo esvaziamento sobre a profissão docente (LOPES, MACEDO, TURA, 2012) e tem, inclusive, afastado muitos profissionais da sala de aula. Notícia veiculada apresenta a estatística de que no ano de 2016, “37.833 professores da rede pública do Estado de São Paulo foram afastados do trabalho por transtornos mentais e comportamentais. A principal causa é a violência física e verbal a que os educadores estão submetidos diariamente" ${ }^{\text {. }}$.

Destituídos de autoridade elegitimidade, convivendo com baixos salários e medo, pressionados por resultados, sem autonomia até em relação à seleção e organização dos conteúdos a serem ensinados, ameaçados e agredidos, não é difícil de entender porque estes professores não gostam da escola.

E os alunos? Inclinamo-nos a pensar que os alunos gostam da escola, o que eles não gostam é de algumas atividades, de algumas aulas, de ter que pensar para aprender. Afinal, aprender é exercer uma atividade em situação: em um local, em um momento de sua história e em condições de tempo diversas, com a ajuda de pessoas que ajudam a aprender (CHARLOT, 2000).

Aprender é uma atividade exercida e não recebida. Para aprender, o aluno precisa se mobilizar, agir, desejar e pensar. Precisa estar engajado, encontrar sentido. Não é uma atividade passiva, antes exige uma ação constante. Aprender implica engajar-se em uma atividade instigante, problematizada, interessante, compreensível, dialogada. Desafiadora, mas não impossível de ser resolvida. Mas lembremos que mesmo com todas essas características sobre o tipo da atividade, enquanto profissionais do ensino, não dominamos nem garantimos a aprendizagem.

Como é possível exercer a ação de aprender? E, acrescentamos, ainda, o que pensam os alunos sobre os professores? E sobre o que se aprende na escola? Que relações são construídas na escola, com os professores e com outros alunos? Que espaço é esse da escola? Será que há esperança? O que seria, então, construir uma cultura da paz?

9 VIOLÊNCIA causa transtornos e afasta quase 40 mil professores da sala de aula na rede estadual de SP. Hoje em dia, São Paulo, março, 2016. Disponível em: <http://entretenimento.r7.com/hoje-em-dia/videos/ violencia-causa-transtornos-e-afasta-quase-40-mil-professores-da-sala-de-aula-na-rede-estadual-desp-31032016>. Acesso em: 24 jun. 2017.

Rev. Pistis Prax., Teol. Pastor., Curitiba, v. 10, n. 1, 36-58, jan./abr. 2018 
Qualquer atividade humana precisa de um espaço e de um tempo determinados. Assim acontece com o ensinar e o aprender; com a educação. Dessa forma entende-se que a escola é pensada para ser um espaço para as práticas de ensino-aprendizagem, tendo um programa específico de necessidades destinadas a prática do educar (FRAGO; ESCOLANO, 2001, p. 61).

A escola é um espaço privilegiado de socialização $0^{10}$ e de trabalho, tem um objeto específico e uma função determinada nas práticas de ensino-aprendizagem, como afirmou Pérez Gómez (1998, p. 13) “educação, num sentido amplo, cumpre uma iniludível função de socialização”, mas antes, tem se tornado espaço apenas de lazer para muitos alunos e alunas e não de aprendizagem.

Outras vezes, este espaço é desinteressante, desorganizado, pouco atrativo, feio e isto nos remete a Anísio Teixeira, ao enfatizar que sem instalações adequadas não pode haver trabalho educativo; assim o prédio, sua estrutura física é condição para o desenvolvimento de qualquer programa educacional, e torna-se indispensável para as práticas e planos de ensino propriamente ditos (DÓREA, 2000, p. 151).

Num espaço inadequado, sem razões para aprender, na convivência com professores desacreditados, por que ainda estar na escola? A essa altura, pode-se considerar que não temos saídas, haja vista que a formação não é possível, então fechemos as escolas. Mas, antes é necessário afirmar que essa conclusão foi demasiadamente precipitada.

Ao apresentar as dificuldades em que se confrontam professores diante de sua ação profissional, queremos evidenciar os conflitos e desafios que essa profissão precisa enfrentar. Assim como remeter a compreensão de que apesar da impossibilidade, estamos "convocados a dar sentido ao mundo, porque somos mobilizados pela busca de estabilizar o caos da existência, de encontrar pontos de aproximação" (LOPES; BORGES, p. 499, 2015). Então, como concluir esse artigo diante dessa convocação?

10 Compreendemos a socialização como a capacidade de fazer amigos, mas não restrita a isto, dessa forma a socialização permite aprender a conviver em sociedade, a incorporação das regras de convivência, conhecimento e reconhecimento dos espaços, limites, direitos e deveres. 


\section{Haverá esperança? Qual o caminho?}

Podemos aceitar a convocação ou cairmos no imobilismo; ceder às pressões externas ou lutar na convicção de que as coisas podem ser configuradas em outros princípios. Seguiremos, entretanto, com a afirmação da necessidade de nos comprometermos com um projeto formativo. Mas quais os princípios desse projeto formativo? Segundo Hoch (1992, p. 108), caberia ser um "posto avançado de escuta". O que significaria este posto avançado? O que devemos escutar? Esclarece o autor: "preocupações e angústias que atormentam as pessoas e a sociedade na atualidade" ( $\mathrm{HOCH}$, 1992, p. 108). Podemos ainda esclarecer como McLaren (2007b, p. 104, 105) "fazerem as pazes, de se voltar a outra face, e de se atravessarem as fronteiras para servir às pessoas antes consideradas 'excluídas' [...] de serviço e de amor, de justiça e de misericórdia, de humildade e de esperança”.

Isso, sim, seria estabelecer as bases para o desenvolvimento da cultura da paz, que busca na presença do outro a descoberta do significado maior de sua humanidade. Humanidade que se afirma na presença de outras espiritualidades, concretizadas nos relacionamentos e nas vivências em prol de um objetivo maior: o ser e existir humanos.

O desenvolvimento da cultura da paz nos obriga a um caminho teológico prático. Grenz e Olson (2013, p. 9), definem teologia "como a reflexão intelectual sobre o ato, o conteúdo e as implicações da fé cristã [...] a teologia serve à Igreja a cada geração e em cada contexto cultural". Aqueles que defendem uma teologia prática realizam projetos que vão além da pregação expositiva dentro dos templos, ampliam a ação através de "Ministérios de recuperação de dependentes de drogas, trabalho com meninos de rua, idosos, prostitutas, deficientes, paralíticos, mães solteiras, presidiários, cegos, órfãos, refugiados, desempregados..." (PADILLA, 2014, p. 33) na luta contra a desigualdade social, injustiça e pobreza, sob a ótica de que "evangelização e a responsabilidade social estão unidas inextricavelmente” (PADILLA, 2014, p. 24).

Partindo dessa compreensão de teologia, "Viver [é] promover a liberdade, a justiça social, viver a essência do amor a qualquer custo, cuidar da natureza, permitir abençoar e ampliar a comunhão cristã [...]" (POMMERING, 2016, p. 10), isto exige a contextualização do texto bíblico para a realidade, até porque, "Uma simples repetição da narrativa é um método expositivo insuficiente e 
ineficaz" (VIRKLER, 2001, p. 164), e, dessa forma, a aplicabilidade permite compreender e viver na possibilidade de enxergar os princípios bíblicos não apenas como relatos históricos, mas modelos para a vida atual.

\section{Considerações finais}

Na possibilidade da existência e construção de um projeto formativo que permita professores e alunos conviverem em respeito, mediados pelo desejo de aprender, nos colocamos ao final desse artigo. Reconhecemos que as relações humanas são contingentes e precárias, e que não há como prever o que vai acontecer, mas colocamo-nos no compromisso e responsabilidade de que é possível novas relações, assim vamos indicando algumas possibilidades e limites para a constituição de um projeto humanizador.

Primeiramente, é possível aprender com as experiências exitosas e existem experiências exitosas: as que promoveram integração entre escolas e comunidades, sobretudo, na necessidade de democratizar a escola, não apenas criando eventos sociais, ou permitindo sua abertura mediante a ocupação dos espaços escolares, nos fins de semana, para o desenvolvimento de atividades esportivas, culturais e de lazer, mas envolvendo as comunidades nos processos decisórios da escola ${ }^{11}$. Entretanto, questionamos: esta solução é aplicável a diversos contextos? Ou em apenas algumas condições é possível promover esse tipo de integração? Essa solução pode ser classificada como bottom-up, ou de baixo para cima, em que agentes fazem decisões coletivas para melhorar a escola. Para tanto, é preciso não apenas capacidade de organização, mas incentivos a diretores e professores para se importarem com a escola e com o cumprimento de sua função: o de trabalhar na perspectiva da aprendizagem dos alunos e alunas e criar um ambiente seguro de socialização.

11 A exemplo temos: São Paulo: Secretaria Municipal de Educação - gestão Mário Covas (1983/1985) estabeleceu o projeto Fim de Semana, que propunha o uso dos espaços escolares, nos fins de semana, com atividades envolvendo professores, alunos, grupos organizados da comunidade e moradores do bairro (SPOSITO, 1993) conf. In: SPOSITO, M. P. A llusão fecunda: a luta por educação nos movimentos populares. In: GONÇALVES, L. A. Práticas contra a violência escolar: a experiência de escolas municipais de Belo Horizonte e Contagem. Belo Horizonte: Grupo de Avaliação e Medidas Educacionais. UFMG, 2000. ainda acrescentamos: <https://gestaoescolar.org.br/conteudo/784/aqui-a-violencia-nao-entra>. 
E quanto às soluções top-down, ou de cima para baixo? O que o Estado pode fazer? Reestruturação das carreiras? Aumento do piso? Como fazer com que professores gostem da escola? Investimento em infraestrutura? Essas coisas todas devem ser feitas a partir de planejamento central, ou é melhor descentralizar recursos e decisões para estados e municípios? Acrescentamos, ainda, que não há como se produzir políticas de combate à violência escolar sem produzir, ao mesmo tempo, políticas de combate à delinquência, que foquem no desenvolvimento de uma cultura da paz. Pois, a "reivindicação da não violência não apenas me interpela como uma pessoa individual que deve agir de uma maneira ou de outra [...] mas sim sobre o que uma recusa em agir pode significar" (BUTLER, 2015, p. 252, 257).

Soma-se a isto o investimento na universalização da educação formal, com a democratização do acesso a ambientes escolares com infraestrutura digna, para o desenvolvimento de projetos educativos que agreguem a arte, o movimento, a descoberta. O investimento público em áreas de lazer e cultura na comunidade.

Por outro lado, afirmamos que o tema da violência em meio escolar não pode mais passar despercebido pelos formuladores das políticas, e finalmente, no compromisso e responsabilidade de um projeto humanizador.

\section{Referências}

ADORNO, S. Exclusão socioeconômica e violência urbana. Sociologias, Porto Alegre, v. 4, n. 8, p. 84-135, 2002.

ARENDT, H. Entre o passado e o futuro. 3. ed. São Paulo: Perspectiva, 1992.

BATELlA, W. B.; DINIZ, A. M. A. Análise Espacial dos Condicionantes da Criminalidade Violenta no Estado de Minas Gerais. Sociedade \& Natureza, Uberlândia, v. 22, n. 1, p. 151-163, abr. 2010.

BATISTA, A. L.; EL-MOOR, P. Violência e agressão. In: CODO, W. (coord.). Educação: carinho e trabalho. Rio de Janeiro: Vozes, 1999.

BALL, S. J.; MAGUIRE, M.; BRAUN, A. Como as escolas fazem as políticas: atuação em escolas secundárias. Trad. Janete Bridon. Ponta Grossa: Editora UEPG, 2016. 
BLANCO, R.; et al. Educação de qualidade para todos: um assunto de direitos humanos. 2. ed. Brasilia: UNESCO, OREALC, 2008.

BRICEÑO-LEÓN, R. La Violencia en América Latina: Salud Pública y Cambio Social. In: BRONFMAN M.; CASTRO, R. (orgs.). Salud, Cambio Social y Política. Perspectivas desde América Latina. México: EDAMEX, 1999.

BUTLER, J. Quadros de Guerra: quando a vida é passível de luto: Civilização Brasileira, Rio de Janeiro, 2015.

CARVALHO NETO, T. Combate ao bullying nas escolas. Revista de Educação Física, n. 38, dez. 2010.

CERQUeIRA, D.; LOBÃO, W. Determinantes da Criminalidade: Arcabouços Teóricos e Resultados Empíricos. Dados - Revista de Ciências Sociais, Rio de Janeiro, v. 47, n. 2, p. 233-269, 2004.

CHAGAS, A. Violência contra professores. Quando a tarefa de ensinar vira caso de violência. Terra, 2010. Disponível em: <http://noticias.terra.com.br/educacao/infograficos/violencia-contra-professores/>. Acesso em: 20 jul. 2017.

CHARLOT, B. Ensinar e formar: a lógica dos discursos e lógica das práticas. In: CHARLOT, B. Relação com o saber, formação de professores e globalização: questões para a educação hoje. Porto Alegre: Artmed, 2005.

CHARLOT, B. Da relação como saber: Elementos para uma teoria. Porto Alegre: Artmed, 2000.

COLLINS, R. Micro and Macro Causes of Violence. International Journal of Conflict and Violence, v. 3, n. 1, p. 9-22, 2009.

DÓREA, C. R. D. Anísio Teixeira e a arquitetura escolar, planejando escolas, construindo sonhos. Revista da FAEEBA, Salvador, n. 13, p. 151-160, jan./jun. 2000.

DURAS, M. O deslumbramento de Lol. V. Stein. Trad. Ana Maria Falcão. Rio de Janeiro: Nova Fronteira, 1986.

ESTUDANTE agride professor após pedido para desligar celular na aula. G1, Rio Preto e Araçatuba, março, 2016. Disponível em: <http://g1.globo.com/sao-paulo/sao-jose-do-rio-preto-aracatuba/noticia/2016/03/estudante-agride-professor-apos-pedido-para-desligar-celular-na-aula.html>. Acesso em:15 mar. 2016. 
FRAGO, V. A.; ESCOLANO, A. Currículo, espaço e subjetividade: a arquitetura como programa. Trad. Alfredo Veiga-Neto. 2. ed. Rio de Janeiro: Ed. DP7A, 2001.

FREIRE, P. Pedagogia do oprimido. 24. ed. Rio de Janeiro: Paz e Terra, 1985.

FREIRE, P. Professora sim, tia não: cartas a quem ousa ensinar. São Paulo: Editora Olho d’Água, 1997.

GRENZ, S. J.; OLSON, R. E. A teologia do século 20 e os anos críticos do século 21 Deus e o mundo numa era líquida. São Paulo: Cultura Cristã, 2013.

GUIMARÃES, A. M. A dinâmica da violência escolar: Conflito e ambiguidade. Campinas: Autores Associados, 1996.

HEIDRICH, G. Aqui, a violência não entra. Gestão escolar, São Paulo, 1 abr. 2009. Disponível em: <https://gestaoescolar.org.br/conteudo/784/aqui-a-violencianao-entra>. Acesso em: 01 abr. 2009.

HOBBES, T. Leviatã ou matéria, forma e poder de um Estado eclesiástico e civil. Trad. João Paulo Monteiro e Maria Beatriz Nizza da Silva. São Paulo: Abril Cultural, 1974.

HERNÁNDEZ, F. Transgressão e mudança na educação: os projetos de trabalho. Trad. Jussara Haubert Rodrigues. Porto Alegre: Artmed, 1998.

HOCH, L. C. O lugar da teologia prática como disciplina teológica. Estudos Teológicos, v. 32, n. 2, p. 100-112, 1992.

HOLANDA, V. R.; et al. Análise da produção científica nacional sobre a utilização de tecnologias digitais na formação de enfermeiros. Revista Eletrônica de Enfermagem, v. 15, n. 4, p. 1068-1077, out-dez. 2013.

LACLAU, E.; MOUFFE, C. Hegemonia e Estratégia Socialista: Por uma política democrática radical. São Paulo: Intemeios: Brasília, 2015.

LATERMAN, I. Violência eincivilidadena escola. Florianópolis: Letras contemporâneas, 2000.

LOPES A. C.; BORGES, V. Formação docente, um projeto impossível. Cadernos de Pesquisa, v. 45, n. 157, p. 486-507, jul/set. 2015. 
LOPES, A. C.; MACEDO, E.; TURA, M. de L. As representações sociais e os estudos de política de currículo para a formação docente. In: PLACCO, V. M. N. de S; VILLA BÔAS, L. P.S.; SOUSA, C. P. de (org.). Representações sociais: diálogos com a educação. São Paulo: Champagnat/FCC, 2012.

MAÇANEIRO, M. O labirinto Sagrado: ensaios sobre religião, psique e cultura. São Paulo: Paulus, 2011.

McLAREN, B. D. A mensagem secreta de Jesus: desvendando a verdade que poderia mudar tudo. Rio de Janeiro: Thomas Nelson Brasil, 2007a.

McLAREN, B. Everything Must Change: Jesus, Global Crises, and a Revolution of Hope. Tennesee: Thomas Nelson Inc.; Colorado Springs: Helmers Literary Agency, 2007b.

MELO, N. V. de. A ética da Alteridade em Emmanuel Levinas. Porto Alegre: EDIPUCRS, 2003.

ODALIA, N. O que é violência? São Paulo: Brasiliense, 2004.

ORGANIZAÇÃO DAS NAÇÕES UNIDAS (ONU). Declaração Universal Dos Direitos Humanos. Assembleia Geral das Nações Unidas em Paris. 10 dez. 1948. Disponível em: <https://nacoesunidas.org/direitoshumanos/declaracao/>. Acesso em: 26 mai. 2017.

PADILLA, C. R. Missão Integral - O reino de Deus e a igreja. Viçosa: Editora Ultimato, 2014. POMMERENING, C. I. Desafios de uma proposta pneumatológica para o pentecostalismo. Azusa - Revista de Estudos Pentecostais, Joinville, v. 7, n. 1, 2016.

PORTAL, L. L. F. Espiritualidade: uma dimensão essencial na experiência significativa da vida. In: TEIXEIRA, E. F. B.; MÜLLER, M. C; SILVA, J. D. T. da. (orgs.). Espiritualidade e Qualidade de Vida. Porto Alegre: EDIPUCRS, 2004.

PÉREZ GÓMEZ, A. I.; SACRISTAN, G. Compreender e transformar o ensino. São Paulo: Artmed, 1998.

PROFESSOR é agredido por aluno em escola estadual em Pouso Alegre, MG. G1, Sul de Minas, Minas Gerais, junho, 2016. Disponível em: <http://g1.globo.com/ mg/sul-de-minas/noticia/2016/06/professor-e-agredido-por-aluno-em-escola-estadual-em-pouso-alegre-mg.html>. Acesso em: 16 jun. 2016. 
RAINE, A. A anatomia da violência: as raízes biológicas da criminalidade. Porto Alegre: Artmed, 2015.

ROLNIK, R. Exclusão territorial e violência. São Paulo Perspec., v. 13, n. 4, p. 100-111, 1999. ISSN 0102-8839. doi: http://dx.doi.org/10.1590/S0102-88391999000400011. Acesso em: 20 jun. 2016.

RUSSEL, P. Educação Religiosa: fundamentação antropológica cultural da religião segundo Paul Tillich. São Paulo: Paulinas, 2007.

SPOSITO, M. P. A Ilusão fecunda: a luta por educação nos movimentos populares. In: GONÇALVES, L. A. Práticas contra a violência escolar: a experiência de escolas municipais de Belo Horizonte e Contagem. Belo Horizonte: Grupo de Avaliação e Medidas Educacionais. UFMG, 2000.

THORNBERRY, T; HUIZINGA, D; LOEBER, R. The Causes and Correlates Studies: Findings and Policy Implications. Office of Juvenile Justice and Delinquency Prevention, 2004.

VIOLÊNCIA causa transtornos e afasta quase 40 mil professores da sala de aula na rede estadual de São Paulo. Disponível em: <http://entretenimento.r7.com/hoje-em-dia/videos/violencia-causa-transtornos-e-afasta-quase-40-mil-professores-da-sala-de-aula-na-rede-estadual-de-sp-31032016 > Acesso em: 20/7/2017.

VIRKLER, H. A. Hermenêutica avançada: princípios e processos de interpretação bíblica. Trad. Luiz Aparecido Caruso, São Paulo, Editora Vida, 2001.

ZALUAR, A.; LEAL, M. C. Violência extra e Intramuros. Revista Brasileira de Ciências Sociais, v. 16, n. 45, p. 145-164, 2001.

Recebido: 26/07/2017

Received: 07/26/2017

Aprovado: 13/11/2017

Approved: 11/13/2017 